\title{
Mobilizing monocytes to cross-present circulating viral antigen in chronic infection
}

\author{
Adam J. Gehring, ${ }^{1}$ Muzlifah Haniffa, ${ }^{2,3}$ Patrick T. Kennedy, ${ }^{4}$ Zi Zong Ho, ${ }^{1}$ \\ Carolina Boni, ${ }^{5}$ Amanda Shin, ${ }^{3}$ Nasirah Banu, ${ }^{1}$ Adeline Chia, ${ }^{1}$ \\ Seng Gee Lim, ${ }^{6}$ Carlo Ferrari, ${ }^{5}$ Florent Ginhoux, ${ }^{3}$ and Antonio Bertoletti1,7,8
}

\begin{abstract}
${ }^{1}$ Infection and Immunity Programme, Singapore Institute for Clinical Sciences, Agency for Science Technology and Research ( $A^{*}$ Star), Singapore. ${ }^{2}$ Institute of Cellular Medicine, Newcastle University, Newcastle, United Kingdom. ${ }^{3}$ Singapore Immunology Network,

Agency for Science Technology and Research (A*Star), Singapore. ${ }^{4}$ Center for Digestive Disease, Blizard Institute of Cell and Molecular Science, Barts and The London School of Medicine and Dentistry, London, United Kingdom. ${ }^{5}$ Unit of Infectious Diseases and Hepatology, Laboratory of Viral Immunopathology, Azienda Ospedaliero-Universitaria di Parma, Parma, Italy. ${ }^{6}$ Yong Loo Lin School of Medicine, National University of Singapore, Singapore. PProgram Emerging Viral Diseases, Duke-NUS Graduate Medical School, Singapore. ${ }^{8}$ Department of Medicine, Yong Loo Lin School of Medicine, National University of Singapore, Singapore.
\end{abstract}

\begin{abstract}
Selection of antigens for therapeutic vaccination against chronic viral infections is complicated by pathogen genetic variations. We tested whether antigens present during persistent viral infections could provide a personalized antigenic reservoir for therapeutic T cell expansion in humans. We focused our study on the HBV surface antigen (HBsAg), which is present in microgram quantities in the serum of chronic HBV patients. We demonstrated by quantitative fluorescent microscopy that, out of 6 professional APC populations in the circulation, only CD14 monocytes (MNs) retained an HBsAg depot. Using TCR-redirected CD8 ${ }^{+} \mathrm{T}$ cells specific for MHC-I-restricted HBV epitopes, we showed that, despite being constantly exposed to antigen, ex vivoisolated APCs did not constitutively activate $\mathrm{HBV}$-specific $\mathrm{CD8}^{+} \mathrm{T}$ cells. However, differentiation of $\mathrm{HBsAg}^{+}$ CD14 MNs from chronic patients to MN-derived DCs (moDCs) induced cross-presentation of the intracellular reservoir of viral antigen. We exploited this mechanism to cross-present circulating viral antigen and showed that moDCs from chronically infected patients stimulated expansion of autologous $\mathrm{HBV}$-specific $\mathrm{T}$ cells. Thus, these data demonstrate that circulating viral antigen produced during chronic infection can serve as a personalized antigenic reservoir to activate virus-specific $\mathrm{T}$ cells.
\end{abstract}

\section{Introduction}

Therapeutic vaccination for chronic infections, be it recombinant antigens, peptides, viral vectors, DNA, or DCs, are hindered by the need to select appropriate antigens. It is a major complicating factor due to the evolutionary diversity that pathogens have developed in response to selective forces exerted by individual (immune response) or environmental (drugs, vectors) factors. Moreover, peptides covering conserved regions for vaccination are HLA restricted and can only be applied to selected patients with the appropriate HLA. As a result, recombinant antigens or DNA vectors coding pathogen proteins may misdirect the intended immune response due to differences between the infectious pathogen and the antigen sequence utilized for vaccination.

A hallmark of many chronic infections is the constant production of pathogen proteins. This is particularly evident in HBV infection, where viral titers can reach $10^{9}-10^{10}$ virions $/ \mathrm{ml}$ in the serum. The $\mathrm{HBV}$ surface antigen (HBsAg) is produced in excess of whole virions and reaches concentrations well into the $\mu \mathrm{g} / \mathrm{ml}$ range (1). While persistently present viral antigen is generally considered a negative factor (2), the abundance of endogenously produced viral antigen could be internalized by different cell types. Proper activation of cells internalizing antigen in the circulation of chronic patients could provide a target for therapeutic vaccination and stimulate $\mathrm{T}$ cells with antigen customized to the patient's viral genome.

HBV does not infect or productively replicate in human PBMCs (3), and systematic analysis of cells capable of internalizing circu-

Conflict of interest: The authors have declared that no conflict of interest exists. Citation for this article: J Clin Invest. 2013;123(9):3766-3776. doi:10.1172/JCI66043. lating viral antigen has not been performed. However, HBsAg particles are highly immunogenic, and DCs and macrophages from mice cross-present recombinant $\mathrm{HBsAg}$ (rHBsAg) particles to $\mathrm{CD}^{+}$ $\mathrm{T}$ cells in the absence of inflammatory signals (4-7). HBsAg-specific $B$ cells can present antigen captured through the $B$ cell receptor via the MHC-I pathway (8). The core antigen ( $\mathrm{HBcAg}$ ) has been shown to bind membrane Ig on a high frequency of resting B cells and to activate $\mathrm{CD}^{+} \mathrm{T}$ cells (9). These studies have been performed in mice or in vitro model systems and demonstrate that HBV antigens have the ability to activate $\mathrm{HBV}$-specific $\mathrm{CD}^{+} \mathrm{T}$ cells, which play a key role in HBV control (10). Yet, there is no answer as to whether APCs are capable of internalizing antigen in the circulation of patients and, more importantly, whether naturally sequestered antigen can be presented to activate virus-specific $\mathrm{CD}^{+} \mathrm{T}$ cells in humans.

The aim of our study was to determine whether circulating viral antigen can be exploited to activate virus-specific T cells. Because multiple cell types cross-present HBV antigens in model systems, we took a comprehensive approach and used FACS to isolate 6 highly purified populations of DCs, MNs, and B cells ex vivo from chronic HBV patients. We tested the different APCs for the presence of viral antigen captured from the circulation and to determine whether persistent antigen could be cross-presented and used to activate autologous virus-specific $\mathrm{T}$ cells.

\section{Results}

Professional APC frequency and function in chronic HBV patients. Controversy exists in chronic HBV infection as to whether the frequency and function of APCs is intact. Therefore, before investigating questions related to antigen-specific $\mathrm{T}$ cell activation in the circu- 
A
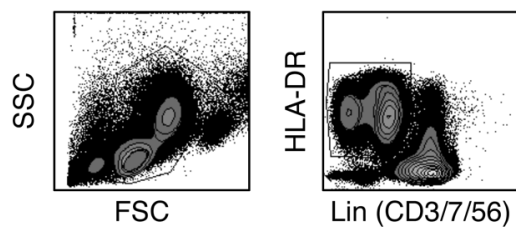

Lin $(\mathrm{CD} 3 / 7 / 56)$
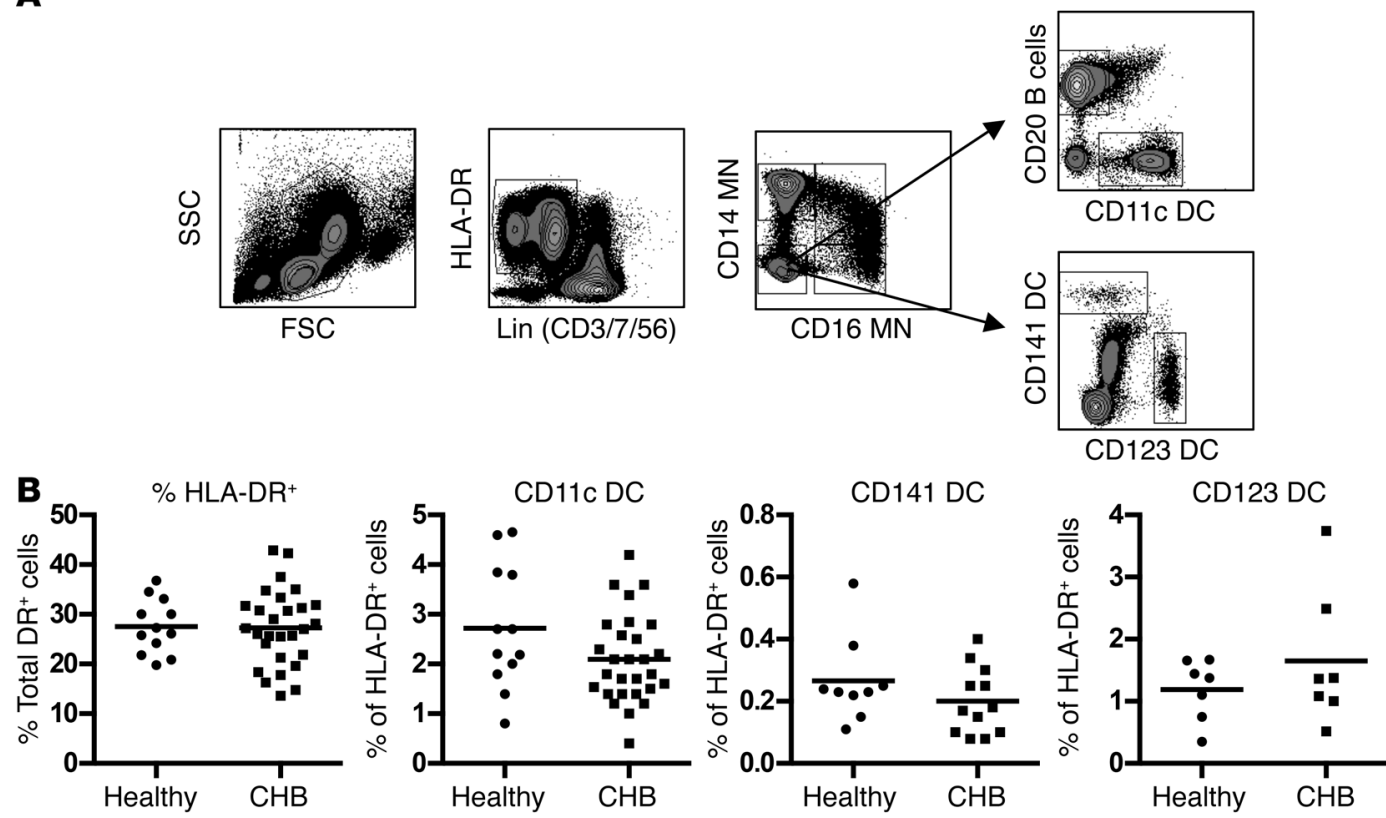

CD14 MN
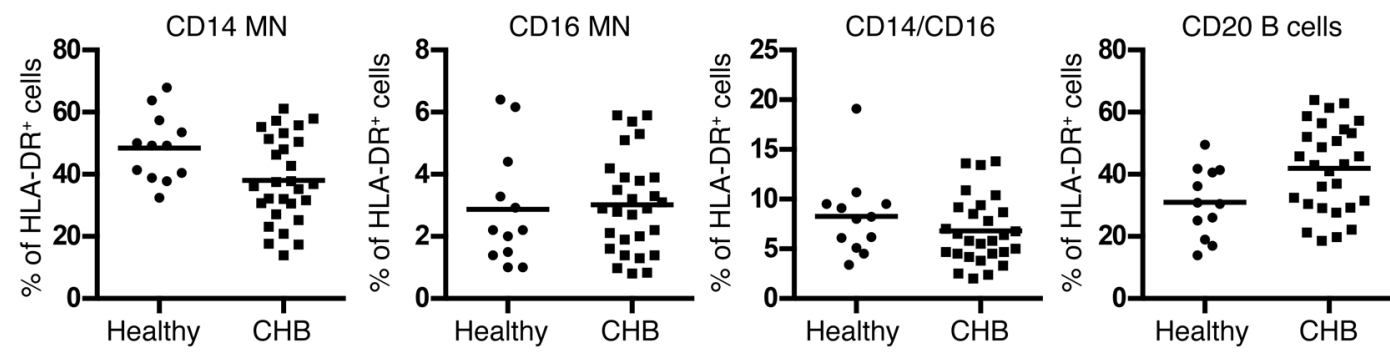

Figure 1

APC gating strategy and population frequency analysis in healthy donors and chronic HBV patients. (A) Lineage-negative (CD3/CD56/CD7) HLA-DR ${ }^{+}$ APCs were derived from total live PBMCs gated by forward and side scatter followed by single-cell gating using width and height parameters with viability dye (data not shown). CD11c mDCs, CD141 DCs, CD123 pDCs, and CD20 B cells were identified from the CD14/CD16 doublenegative population. (B) Frequency of HLA-DR ${ }^{+}$cells in total PBMCs and frequency of specific APC populations as a proportion of $\mathrm{HLA}^{-D R^{+}}$ cells. There were no statistically significant differences determined by 1-way ANOVA and Tukey's post-test analysis using total CHB patients; information on patients categorized by viral load and liver inflammation is displayed in Supplemental Figures 1 and 2.

lation, we characterized the APC compartment in 28 chronic HBV patients (Supplemental Table 1; supplemental material available online with this article; doi:10.1172/JCI66043DS1). Analysis of the frequency of total APCs (HLA-DR ${ }^{+}$) or 7 distinct APC populations ex vivo (Figure 1A; myeloid DCs [mDCs], CD141 DCs, CD123 plasmacytoid DCs (pDCs), CD14 monocytes [CD14 MNs], CD14/ CD16 MNs, CD16/CD14 low MNs [CD16 MNs], and CD20 B cells) did not show any significant differences between chronic HBV patients and healthy controls (Figure 1B). The frequency of APCs was not altered by viral load (Supplemental Figure 1) or liver inflammation (Supplemental Figure 2). We did find that the frequency of CD14 MNs tended to be lower in chronic HBV patients, while the frequency of CD20 B cells tended to be increased, but these differences were not significant.

We tested the stimulatory capacity of 4 of the APC populations using allogeneic mixed lymphocyte reactions (MLR) where sufficient numbers could be consistently obtained. The division index and proliferation index were calculated for $\mathrm{T}$ cells after coculture with sorted APCs. Similar to their frequency, we did not observe any significant differences in the ability of professional APCs from chronic HBV patients (Supplemental Table 2) to stimulate proliferation compared with healthy donors (Figure 2). This suggests that at least these 4 APC populations from chronic HBV patients are not inherently inhibitory.

HBsAg in ex vivo-isolated APCs. Having shown that the frequency and function of APCs was generally intact in our cohort of chronic HBV patients, we began to investigate whether circulating HBV antigen could be internalized by APCs in the blood. Previous reports demonstrated the presence of HBV in DCs using PCR and electron microscopy $(3,11)$. However, due to the sensitivity of these assays and limited quantitative data from electron microscopy, controversy remains as to whether it is accurate or due to trace contamination with serum or cells. To clarify this issue, we sorted 6 APC populations, stained them for HBsAg, and analyzed the cells using the Tissuefax system, as it allows for quantitative analysis of fluorescent microscopy data.

Only CD14 MNs in the circulation of chronic patients stained positive for HBsAg; CD16 MNs, mDCs, CD141 DCs, pDCs, and B cells were negative, with background similar to what is observed in healthy controls (Figure 3, A and B). CD14 MNs were positive for 

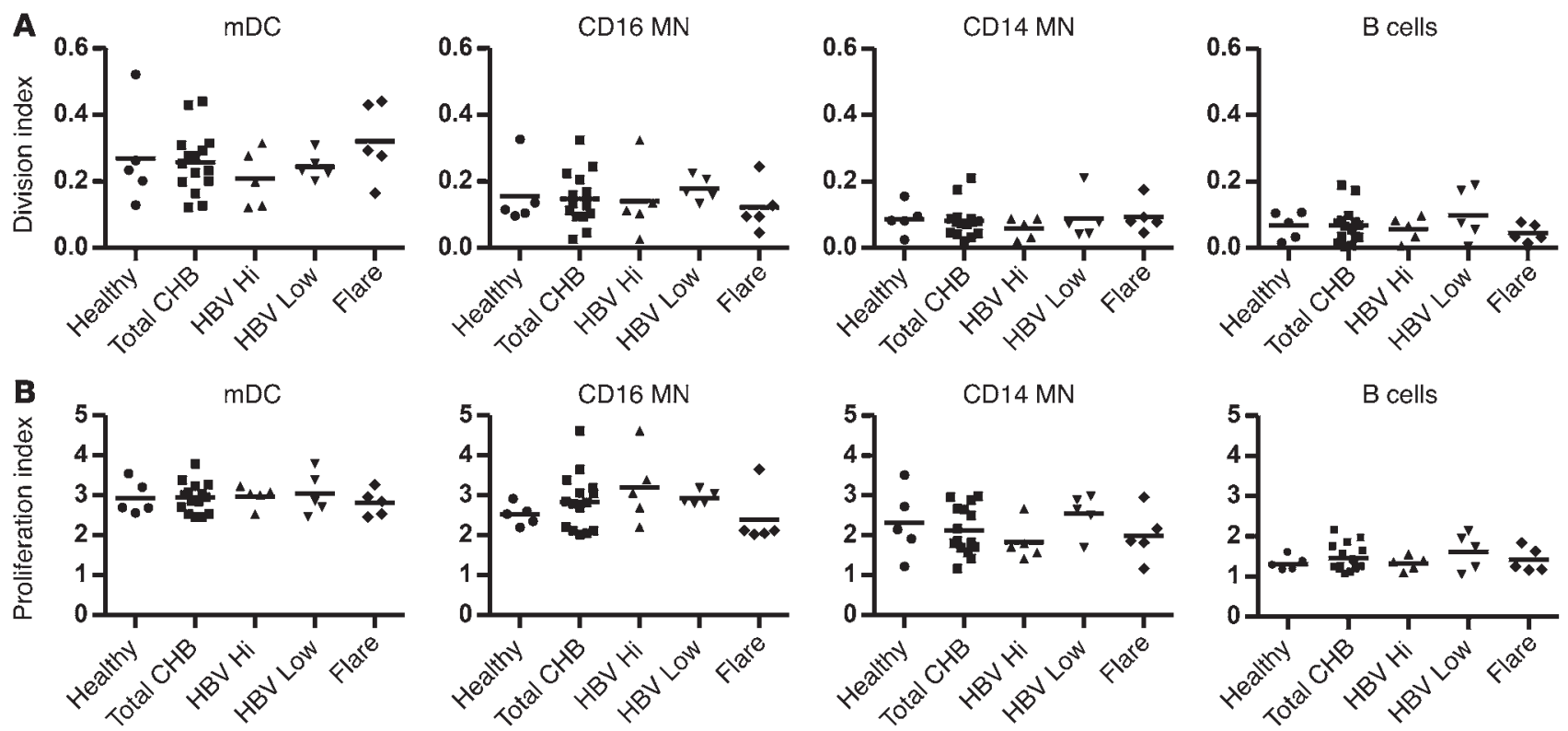

Figure 2

T cell proliferation following coculture with chronic HBV patient APCs. (A) Frequency of T cells induced to proliferate with each APC population in healthy subjects or different HBV cohorts (HBV high [hi] > 106 copies $/ \mathrm{ml}$; HBV low $\leq 10^{6} \mathrm{copies} / \mathrm{ml}$; flare ALT > 500 U/I). (B) Normalized proliferation index with each APC population. Five patients were tested in each cohort. There were no statistically significant differences.

HBsAg in 12 out of 19 patients tested (Supplemental Table 3). The frequency of $\mathrm{HBsAg}^{+} \mathrm{CD} 14 \mathrm{MNs}$ ranged from $20 \%$ to $96 \%$ with a mean of $43 \%$ (Figure 3C). Similar to the representative patient shown, CD16 MNs, mDCs, CD141 DCs, pDCs, and B cells were negative for HBsAg after screening multiple patients (Figure 3C). Thus, CD14 MNs are the only cell population carrying a detectable depot of viral antigen in the circulation of chronic HBV patients.

Since $\mathrm{HBsAg}^{+} \mathrm{CD} 14 \mathrm{MNs}$ were not detectable in all patients $(n=7)$, we determined whether HBsAg staining in CD14 MNs correlated with viral parameters (HBV DNA and $\mathrm{HBsAg}$ ). In the 12 patients that showed HBsAg staining in CD14 MNs, higher viral load correlated with higher frequencies of $\mathrm{HBsAg}^{+} \mathrm{CD} 14 \mathrm{MNs}$ (Figure 3D). However, this was inconsistent because some patients with low viral load $\left(<10^{3}\right)$ showed $\mathrm{HBsAg}^{+} \mathrm{CD} 14 \mathrm{MNs}$ similar to those with HBV-DNA levels of $10^{4}-10^{5}$ (Figure 3D). Furthermore, HBsAgnegative CD14 MNs were found in patients with HBV DNA similar to those that stained positive (data not shown). We also observed that a $3 \log _{10}$ drop in viral load in a patient on antiviral therapy did not influence HBsAg staining, all suggesting that HBsAg positivity is not directly related to viremia (Figure 3E).

We then analyzed whether only HBsAg levels directly correlate with $\mathrm{HBsAg}^{+}$staining in CD14 MNs. We selected 5 patients under antiviral therapy in which HBV DNA values were negative by clinical testing but who had increasing levels of HBsAg in the serum. A dose-dependent increase in $\mathrm{HBsAg}^{+} \mathrm{CD} 14$ MNs occurred as HBsAg increased in the circulation (Figure $3 \mathrm{~F}$ ), confirming that detection of $\mathrm{HBsAg}^{+} \mathrm{CD} 14 \mathrm{MNs}$ is directly related to the level of circulating viral antigen. Staining became maximal at approximately $3306 \mathrm{IU} / \mathrm{ml}$ HBsAg (equivalent $\approx 18.5 \mu \mathrm{g} / \mathrm{ml}$ ). The lowest concentration tested, $606 \mathrm{IU} / \mathrm{ml}(\approx 3.3 \mu \mathrm{g} / \mathrm{ml})$, was just above background staining (data not shown), indicating that the detection threshold for HBsAg staining has a cutoff of roughly $3 \mu \mathrm{g} / \mathrm{ml}$ HBsAg in the serum.
Testing ex vivo MHC-I presentation by APCs using HBsAg-specific redirected $T$ cells. Next, we investigated whether in vivo-captured HBsAg can be constitutively presented on HLA-class I to HBV-specific $\mathrm{CD}^{+} \mathrm{T}$ cells. We used TCR gene transfer to engineer HBV-specific $\mathrm{T}$ cells (12). Lymphocytes of healthy donors were transduced with HLA-A2 or HLA-Cw08 restricted HBsAg-specific TCRs and used to detect MHC-I antigen presentation in all subsequent functional assays (Supplemental Figure 3).

We sorted APCs from 7 chronic HBV patients and 4 healthy donors (Supplemental Table 4). Purified APCs were cocultured with appropriately matched, HLA-restricted HBsAg-specific TCRredirected $\mathrm{T}$ cells. $\mathrm{T}$ cell activation, measured by IFN $-\gamma$ production, was used to determine whether ex vivo APCs isolated from chronic HBV patients presented HBsAg epitopes on MHC-I. Coculture with APCs of either healthy donors or chronic HBV patients ex vivo did not stimulate any significant $\mathrm{T}$ cell IFN- $\gamma$ production as measured by IFN- $\gamma$ ELISPOT (Figure 4). The negative results were confirmed using flow cytometry to monitor T cell IFN- $\gamma$ production (data not shown). We then determined whether inflammatory stimuli (adjuvants) could induce the cross-presentation of in vivocaptured antigen by ex vivo-isolated APCs. Sorted mDCs, CD14 MNs, CD16 MNs, or B cells were activated with TLR-3, -4 , and -9 ligands, IFN- $\alpha$, or IFN- $\gamma$ and cocultured with HBsAg-specific TCRtransduced T cells. Similarly, under these conditions, we did not observe any $\mathrm{T}$ cell activation, indicating that even after short-term activation, mDCs, CD14 MNs, CD16 MNs, or B cells did not crosspresent circulating HBsAg (Figure 4A).

Three chronic HBV patients had sufficient cell numbers to directly test cross-presentation by CD141 DCs and pDCs. pDCs have been shown to cross-present apoptotic debris or lipoproteins following TLR-7 or influenza stimulation (13, 14). CD141 DCs have recently been described as the human equivalent of the murine CD8 $\alpha$ subset, capable of efficiently cross-presenting 
A

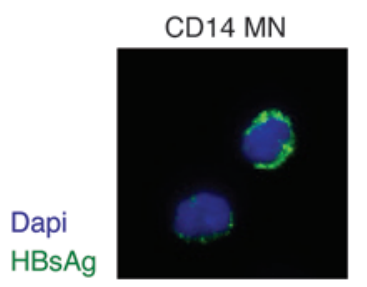

B

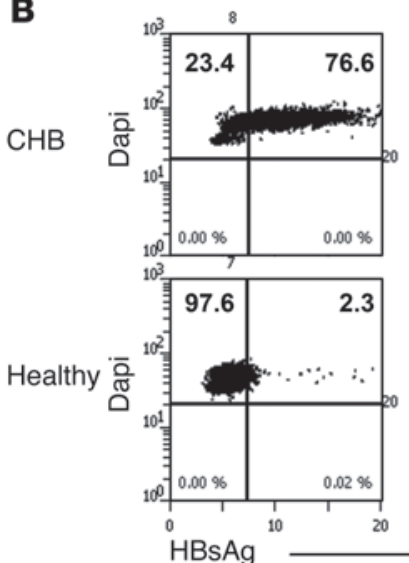

CD16 MN

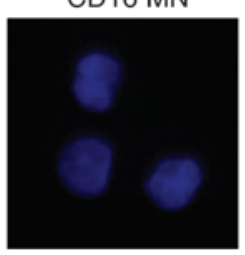

$\mathrm{mDC}$

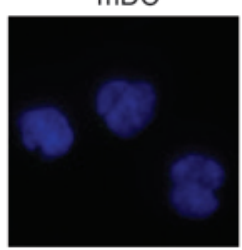

CD141 DC

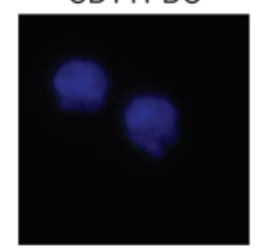

CD123 pDC

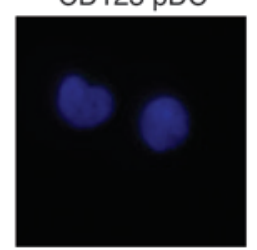

B cell

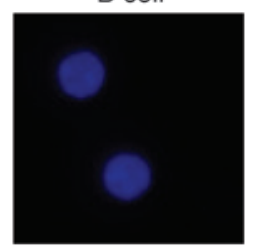

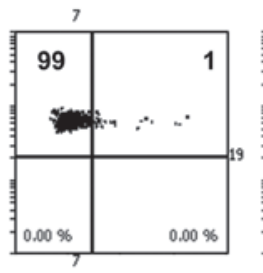
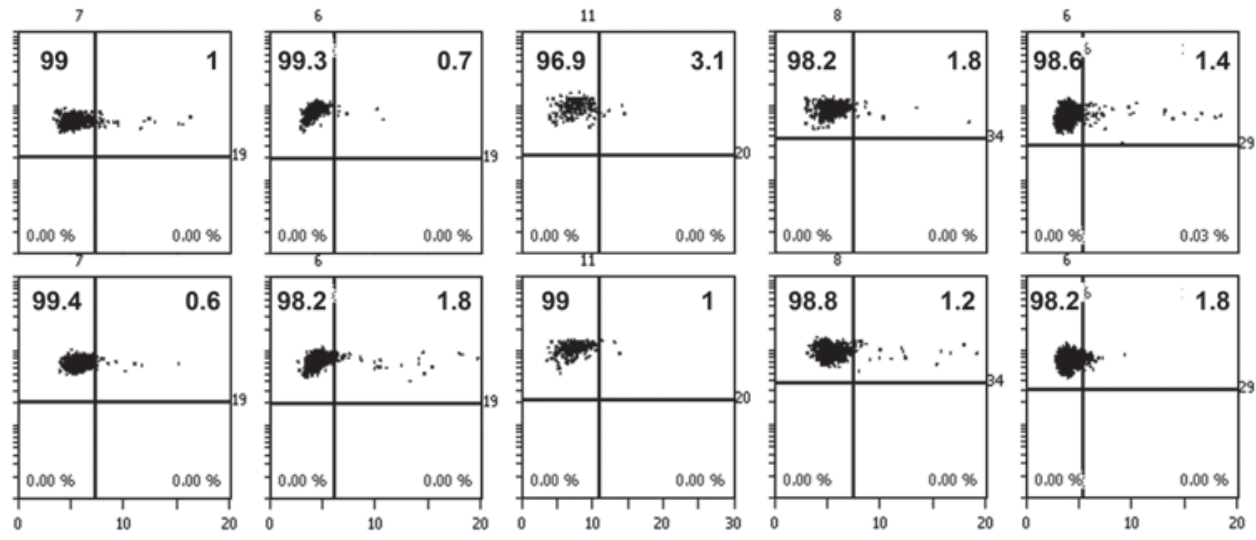

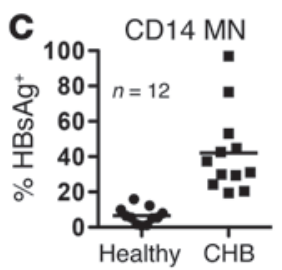

D

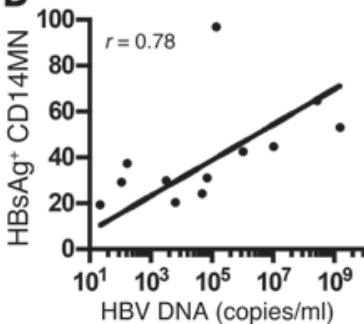

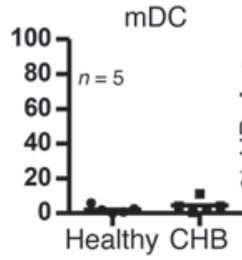
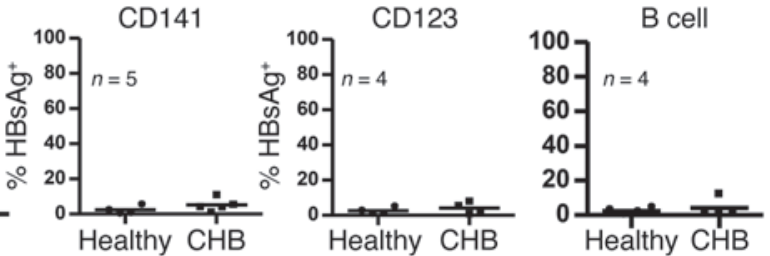

E

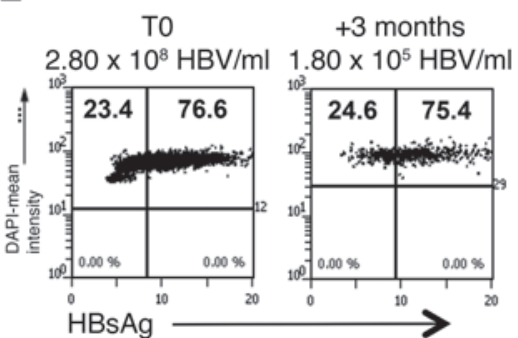

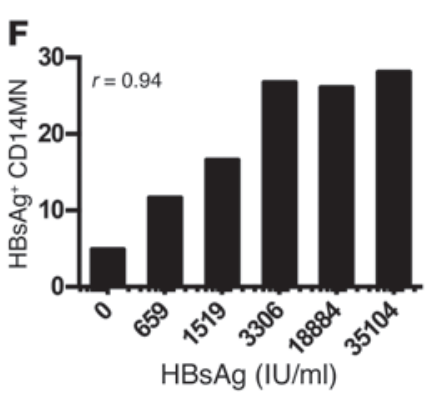

Figure 3

HBsAg staining in FACS-sorted APC populations. (A) Representative fluorescent microscopy images of 6 different APCs sorted from a chronic HBV patient and stained for HBsAg (green) and DAPI (blue). Original magnification, $\times 20$. (B) Dot plot showing quantitative data derived from fluorescent images of each cell population acquired on Tissuefax system. TissueQuest 3.0 was used to analyze each cell (DAPI+ event) for the presence of HBsAg (FITC+ event). Dot plots for 1 representative chronic HBV patient (CHB; top row) and 1 healthy donor (bottom row) are presented. (C) Compilation of the frequency of $\mathrm{HBsAg}^{+}$cells from multiple patients for each APC population. (D) Frequency of HBsAg+ CD14 MNs plotted against viral load in 12 patients with $\mathrm{HBsAg}^{+} \mathrm{CD} 14 \mathrm{MNs}$. (E) HBsAg staining in a patient under antiviral therapy. Longitudinal analysis did not show any reduction in HBsAg staining despite a $3 \log _{10}$ decrease in viral load. (F) CD14 MNs stained for HBsAg from patients with undetectable HBV DNA and known HBsAg quantities.

antigen in humans after activation by poly(I:C) (15-18). Neither resting $\mathrm{pDCs}$ nor $\mathrm{pDCs}$ activated with a panel of TLR ligands and IFN- $\alpha$ activated HBsAg-specific T cells ex vivo (Figure 4B). Fewer conditions were tested with CD141 DCs due to the limited cell numbers, but neither nonactivated nor poly(I:C)-activated CD141 DCs from chronic HBV patients stimulated $\mathrm{CD}^{+} \mathrm{T}$ cells directly ex vivo (Figure 4C). However, CD141 DCs, unlike pDCs, efficiently cross-presented rHBsAg (sAg) loaded exogenously when stimulated with poly(I:C) (Figure 4, B and C).
Thus, no constitutive or inducible ex vivo cross-presentation of HBsAg was detected in the 6 different APC populations tested. T cells and APCs were functional as peptide-loaded APCs of chronic patients stimulated T cell IFN- $\gamma$ production at a level similar to those of healthy donors (Figure 4 and data not shown). Moreover, the ability of CD141 DCs to cross-present soluble antigen was not altered by HBV persistence. We also tested whether HBV core antigen $(\mathrm{HBcAg})$ was presented to HLA-A2-restricted CD8 ${ }^{+}$ T cells ex vivo utilizing HBcAg-specific TCR redirected (c18-TCR) 
A

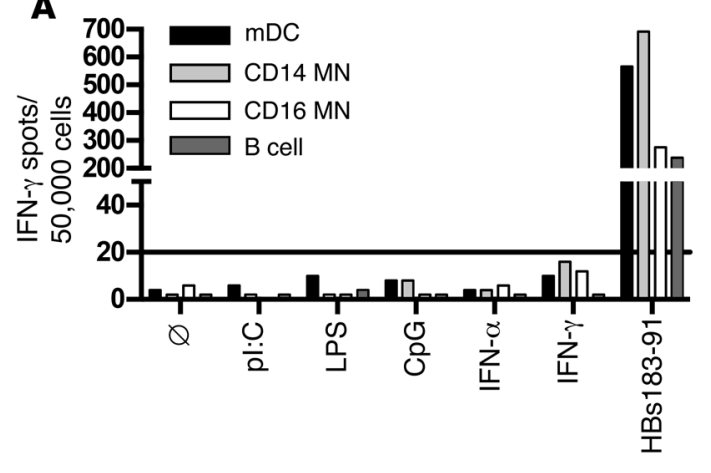

B

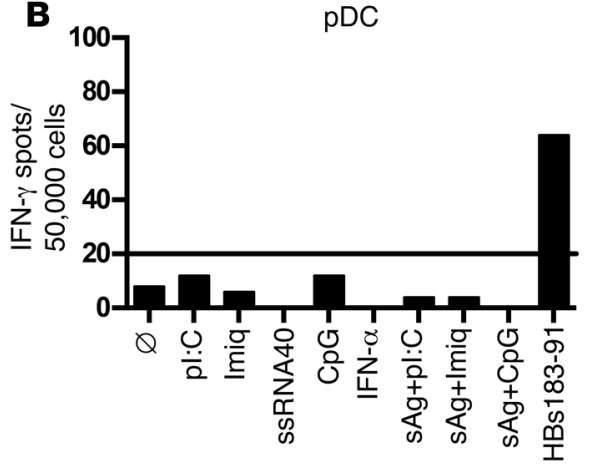

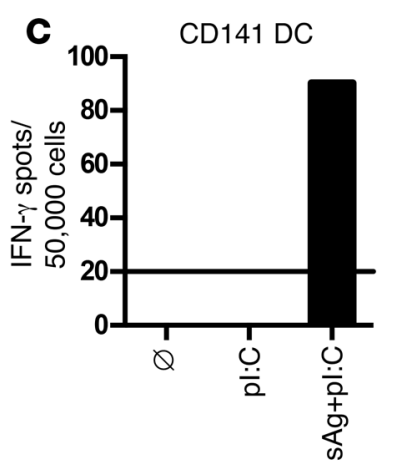

Figure 4

No detectable constitutive or inducible ex vivo cross-presentation. S183-TCR T cell IFN- $\gamma$ ELISPOT following overnight coculture with (A) mDCs, CD14 MNs, CD16 MNs, and B cells; (B) pDCs; (C) CD141 DCs sorted from a representative chronic HBV patient. APCs were left untreated (Ø) or activated overnight with TLR ligands, IFN- $\alpha$, or IFN- $\gamma$, then cocultured with s183-TCR T cells. All cell types were able to present exogenously added peptide. Data in $\mathbf{A}$ are representative of 7 patients; data in $\mathbf{B}$ and $\mathbf{C}$ are representative of 3 patients.

T cells. Similar to HBsAg-specific $\mathrm{T}$ cells, we did not observe any $\mathrm{T}$ cell activation with APCs from 4 HLA-A0201 chronic HBV patients (data not shown). Therefore, even though the major populations of APCs in the circulation of chronic HBV patients are constantly exposed to viral antigen (HBsAg and $\mathrm{HBcAg}$ ), they do not constitutively process and present the antigen via the MHC-I pathway to $\mathrm{CD}^{+} \mathrm{T}$ cells.

Cross-presentation of in vivo-captured HBsAg by $M N$-derived DCs from patients. Since CD14 MNs are the predominant $\mathrm{HBsAg}^{+} \mathrm{APC}$ population, we hypothesized that their differentiation to DCs could permit cross-presentation of captured HBV antigens. We initially tested this by loading healthy donor CD14 MNs with increasing amounts of rHBsAg at day 0 (Figure $5 \mathrm{~A}$ ). The CD14 MNs were differentiated to MN-derived DCs (moDCs) with GM-CSF and IL-4, and cross-presentation was monitored using TCR-redirected CD8 ${ }^{+}$ $\mathrm{T}$ cells. Differentiation alone resulted in dose-dependent crosspresentation of $\mathrm{HBsAg}$ to virus-specific $\mathrm{CD} 8^{+} \mathrm{T}$ cells, which was enhanced with moDC activation (Figure 5B).

We then tested whether viral antigen naturally captured by CD14 MNs from the patient circulation in vivo can be presented to $T$ cells after ex vivo DC differentiation. Purified CD14 MNs from 14 chronic HBV patients (Supplemental Table 5) were stained for HBsAg ex vivo to determine their antigen content and differentiated to moDCs for 6 days in the presence of IL-4 and GM-CSF. Cross-presentation of in vivo-captured HBsAg was monitored using TCR-redirected $\mathrm{CD}^{+} \mathrm{T}$ cells. moDCs from 5 HLA-A0201 ${ }^{+}$ chronic patients were tested with HLA-A0201-restricted HBs183-91 epitope-specific $\mathrm{T}$ cells, while moDCs derived from 4 HLA-Cw0801+ chronic patients were tested with HLA-Cw0801restricted HBs171-80 epitope-specific T cells. moDCs from 5 HLA-mismatched chronic HBV patients and 3 HLA-matched healthy donors served as negative controls.

Ex vivo HBsAg staining of CD14 MNs was observed in 7 out of 9 HLA-matched patients and in all 5 HLA-mismatched patients (Figure 6A). Only 1 patient, chronic HBV-8 (CHB-8), showed HBsAg staining following differentiation to moDCs (data not shown). Upon differentiation alone, robust $\mathrm{T}$ cell activation was detected in 6 of 9 HLA-matched chronic HBV patients (Figure 6B). moDCs from HLA-matched healthy subjects or HLA-mismatched chronic HBV patients did not stimulate any significant $\mathrm{T}$ cell acti- vation (Figure 6B). Activation of moDCs resulted in increased $\mathrm{T}$ cell responses; with a total of 8 of 9 moDCs derived from HLAmatched chronic HBV patients able to elicit a positive $\mathrm{T}$ cell response (Figure 6C). Activation of HLA-matched healthy or HLAmismatched moDCs from chronic patients did not result in any significant increase in HBV-specific $\mathrm{T}$ cell activation.

We did observe variability in responses. Patient CHB-6 did not show any HBsAg staining in CD14 MNs ex vivo, but was capable of activating HBs183-91-specific T cells upon moDC differentiation, suggesting that HBsAg levels of $3 \mu \mathrm{g} / \mathrm{ml}$ and below (limit of our HBsAg staining assay) can be efficiently cross-presented. Conversely, patient CHB-9, with $\mathrm{HBsAg}^{+} \mathrm{CD} 14 \mathrm{MNs}$ was unable to trigger HBV-specific T cells, perhaps due to the presence of an escape mutation in the HBV epitope. In contrast, CHB-8, the one patient with detectable HBsAg in moDCs following differentiation, showed the greatest $\mathrm{T}$ cell response upon activation with poly(I:C). Taken together, these data show that it is possible to differentiate $\mathrm{HBsAg}^{+} \mathrm{CD} 14 \mathrm{MNs}$ from the blood of chronic $\mathrm{HBV}$ patients and harness the sequestered viral antigen to activate virus-specific $\mathrm{CD}^{+} \mathrm{T}$ cells.

Expansion of autologous virus-specific $T$ cells using moDCs presenting in vivo captured HBsAg. Finally, we determined whether cross-presentation of in vivo-captured antigen by moDCs could be used to expand autologous HBV-specific T cells in chronic HBV patients. HBV-specific T cells are functionally and numerically impaired in chronic HBV patients (19), but can still be detected in low numbers in young adults (20), patients under anti-viral therapy (21), or those with low HBV-DNA (22). We tested 20 patients (Supplemental Table 6), 16 under antiviral therapy and an additional 4 that were treatment naive (CHB-29-32). We isolated CD14 MNs from each patient and differentiated them to moDCs with GM-CSF plus IL-4. The moDCs were activated with LPS plus CD40L and cocultured with autologous PBMCs for 10 days, relying only on in vivo-captured antigen to expand virus-specific $T$ cells. In parallel, PBMCs were expanded using a standard approach with 15-mer overlapping peptides covering $\mathrm{HBsAg}$ and $\mathrm{HBcAg}$ to compare responses between the 2 methods.

As expected (19), isolated patient cells did not exhibit virus specific responses ex vivo (data not shown). $T$ cells specific for both $\mathrm{HBcAg}$ and HBsAg could instead be expanded in 16 patients after 

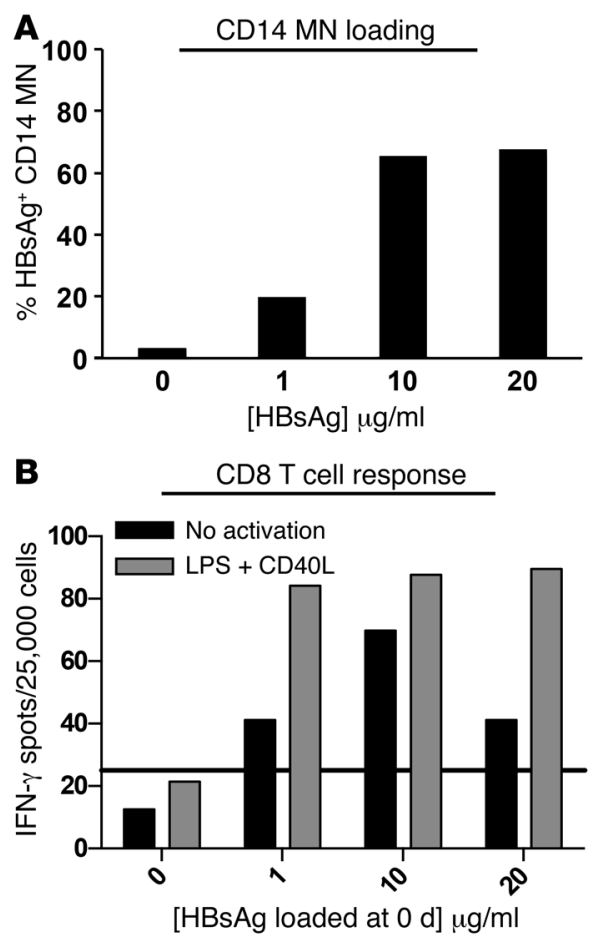

Figure 5

Cross-presentation by healthy donor moDCs loaded prior to differentiation. (A) Isolated CD14 MNs were loaded with increasing concentrations of rHBsAg for 4 hours prior to differentiation and stained for HBsAg to confirm uptake. (B) Differentiated moDCs that were loaded at 0 days were cocultured with s183-TCR CD8 ${ }^{+} \mathrm{T}$ cells \pm LPS/CD40L activation, and cross-presentation was monitored by $\mathrm{T}$ cell activation in IFN- $\gamma$ ELISPOT. Data represent the mean of duplicate wells. This is a representative graph from 3 healthy donors tested in 4 separate experiments.

10 days of in vitro culture with synthetic peptide pools (Figure 7A). More importantly, PBMCs expanded with GM-CSF + IL-4 moDCs (GM/4-DCs), presenting in vivo captured HBV antigen, resulted in HBV-specific T cell expansion in 6 of 20 patients (Figure 7B). Expansion of virus-specific T cells was not only restricted to circulating $\mathrm{HBsAg}$, but also resulted in the expansion of $\mathrm{HBcAg}$-specific $\mathrm{T}$ cells. No $\mathrm{T}$ cell responses to $\mathrm{HBV}$ polymerase or $\mathrm{X}$ proteins were detected (data not shown). These data suggest that, in addition to $\mathrm{HBsAg}$, either $\mathrm{HBeAg}$, the soluble form of $\mathrm{HBcAg}$, or $\mathrm{HBcAg}$ internalized as part of whole virions can be processed and presented to expand virus-specific T cells.

Fewer responses were observed with GM/4-DCs compared with peptides. Boosting virus-specific T cell expansion with GM/4-DCs by blocking PD-L1 and CTLA-4 or inhibiting Bim-mediated apoptosis, 2 pathways known to increase HBV-specific T cell responses $(23,24)$, was ineffective (data not shown). We then tested whether the moDC differentiation program would affect virus-specific $T$ cell expansion to determine whether (a) there is flexibility in how CD14 MNs can be induced to cross-present antigen and (b) whether different types of moDCs might be more efficient at expanding autologous T cells. moDCs made with GM-CSF + IL-15 have been shown to be highly efficient at activating $\mathrm{CD}^{+} \mathrm{T}$ cells $(25)$. Therefore, we compared the ability of GM/4-DCs and GM-CSF + IL-15 (GM/15-DCs) moDCs to expand virus-specific T cells in $14 \mathrm{CHB}$ patients. Figure 7C shows that HBV-specific T cells were expand- ed in 7 of 14 patients by GM/15-DCs and that GM/15-DCs did enhance $T$ cell responses compared with GM/4-DCs in 6 patients (CHB-5, -14, -18, -26, -28, -31).

The moDC-expanded $\mathrm{T}$ cells were functionally characterized with intracellular cytokine staining. moDCs presenting the in vivo captured antigen were capable of expanding both $\mathrm{CD}^{+}$(Figure 7D) and $\mathrm{CD}^{+}$(Figure 7E) T cells. However, these cells displayed an exhausted functional phenotype and produced only IFN- $\gamma$, but not TNF- $\alpha$ or IL-2 (data not shown).

The specificity of the T cells expanded by DCs largely overlapped with that of PBMCs expanded with synthetic peptides (Figure 7A). However, patients CHB-25, -26, and -28 did show an HBV-specific $\mathrm{T}$ cell response in the absence of any positive responses with peptides. We do not have enough data to make any firm conclusions, but this response could be due to differences between the consensus synthetic peptides and the endogenous antigen presented by moDCs. Overall, these data confirm that the depot of viral antigen present in circulating MNs can serve as a personalized antigenic reservoir to expand autologous virus-specific $\mathrm{T}$ cells.

\section{Discussion}

The aim of our study was to determine whether persistent antigen present during chronic viral infection could serve as a personalized antigenic reservoir to activate antigen-specific $T$ cells for potential therapeutic intervention. The persistent presence of high quantities of virions and viral antigens in the circulation of patients with chronic hepatitis B has been associated with the immunological alterations present in these patients. Specifically, that persistent exposure to $\mathrm{HBV}$ and $\mathrm{HBsAg}$ alters the frequency and function of myeloid, plasmacytoid, and moDCs $(11,26-35)$. The previous reports regarding the HBsAg inhibitory effects were largely related to TLR-mediated cytokine production and could affect innate immunity pathways. However, our analyses of the T cell stimulatory function of different APCs ex vivo did not show any significant alterations. Despite marked heterogeneity between different subjects, we did not find any significant quantitative alterations in circulating MNs, DCs, or B cells. The APCs of chronic patients stimulated $T$ cell proliferation in MLR reactions, efficiently activated $\mathrm{HBV}$-specific T cells when loaded with synthetic peptides, and preserved, as in the case of CD141 DCs, their cross-presentation capacity. Combined with the data demonstrating that crosspresentation could be induced in MNs upon differentiation to DCs suggests that antigen processing and presentation are not affected in chronic HBV patients. Therefore, the circulating viral antigen does not alter the functionality of different APCs. To the contrary, circulating antigen selectively captured by CD14 MNs can be used to our advantage as a personalized antigenic reservoir to activate virus-specific T cells in chronic HBV patients.

Circulating HBsAg was undetectable in 5 out of 6 APC populations tested, but was internalized and retained at detectable levels selectively by CD14 MNs. Our staining showed that the frequency of $\mathrm{HBsAg}^{+} \mathrm{CD} 14 \mathrm{MNs}$ did not change significantly with antiviral therapy, which reduced viral load, but was directly correlated with the amount of circulating HBsAg in chronic patients. However, due to the detection threshold of our assay, we were unable to effectively visualize $\mathrm{HBsAg}^{+} \mathrm{CD} 14 \mathrm{MNs}$ ex vivo below $3 \mu \mathrm{g} / \mathrm{ml}$ HBsAg in the serum. Our detection threshold did not reach the sensitivity of our $\mathrm{T}$ cell assays, where we observed $\mathrm{T}$ cell activation by moDCs derived from HBsAg-negative CD14 MNs from chronic patients, suggesting that naturally captured antigen below our 
A

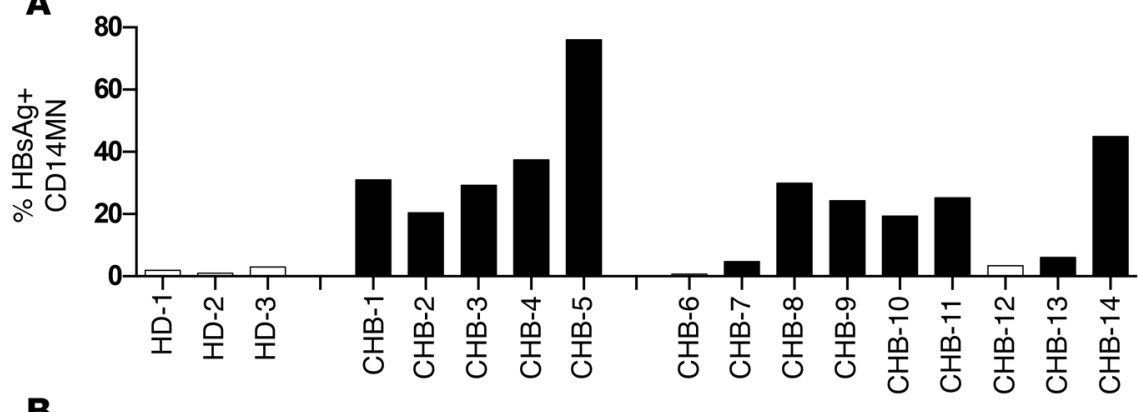

B

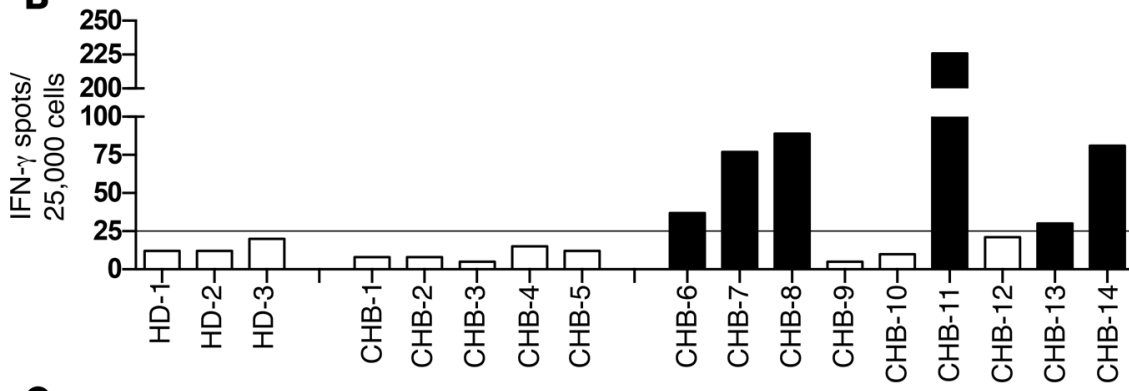

C

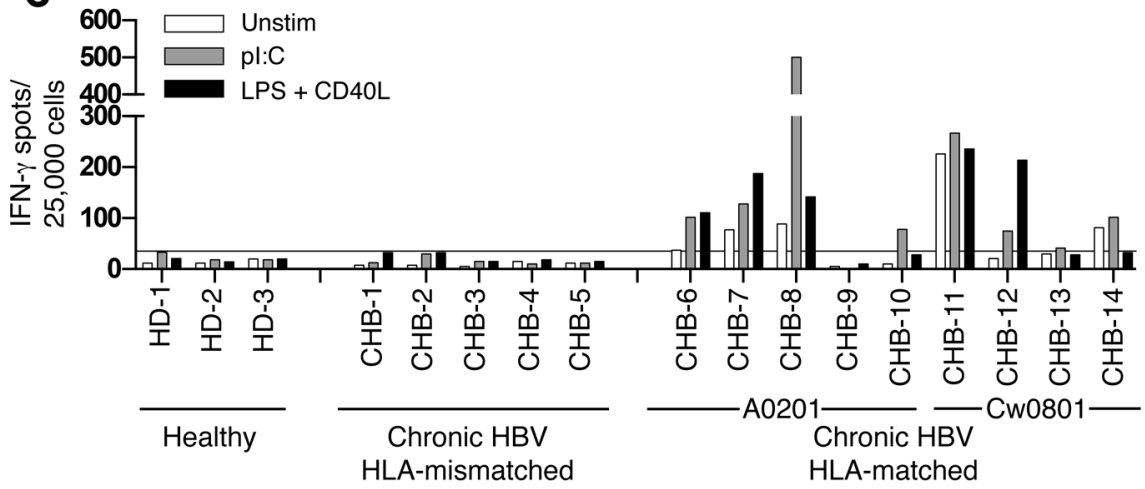

Figure 6

moDCs from patients cross-present in vivo captured HBsAg. (A) HBsAg staining in CD14 MNs isolated from chronic HBV patients. (B) Cross-presentation of circulating in vivo-captured HBsAg following coculture of s183-TCR and $\mathrm{s} 171-\mathrm{TCR} C D 8^{+} \mathrm{T}$ cells with differentiated moDCs in the absence of activation. Healthy donor and HLA-mismatched chronic HBV patient moDCs served as negative controls. Positive responses in HLA-matched moDCs are shown in black. (C) Activation of moDCs can increase the $T$ cell response. moDCs were activated overnight with poly(I:C) or LPS + CD40L and then cocultured with s183-TCR and s171-TCR CD8 ${ }^{+} \mathrm{T}$ cells. detection limit is also efficiently processed. We were surprised that only CD14 MNs stained positive for HBsAg. It is possible that circulating DCs degrade viral antigen rapidly, preventing accumulation to levels detectable by fluorescent microscopy, or that APCs cross-presenting $\mathrm{HBV}$ antigens in the circulation are eliminated by endogenous virus-specific $\mathrm{T}$ cells.

Nevertheless, we did not find direct ex vivo evidence for constitutive or inducible cross-presentation in the circulation. These results strongly suggest that the virus-specific $T$ cell exhaustion seen during persistent $\mathrm{HBV}$ infection in patients is not due to repeated systemic activation mediated by circulating APCs. Rather, $\mathrm{T}$ cell exhaustion is likely the result of persistent presentation of viral antigen in the liver by infected hepatocytes and nonclassical APCs, similar to what has been demonstrated in mice (36-38). However, we cannot rule out the impact that inflammatory conditions might have on circulating CD14 MNs. Circulating MNs are precursors for inflammatory DCs. It has been demonstrated that acute viral infections such as influenza cause rapid differentiation of blood MNs to mature DCs (39). This could lead to presentation of the antigen depot and affect the HBV-specific immune response or pathogenesis of chronic HBV infection. Whether this actually occurs and whether this would be advantageous or deleterious remains to be determined.
While there was no ex vivo cross-presentation, we clearly show that the antigen stored in CD14 MNs of chronic HBV patients could be efficiently presented to virus-specific $\mathrm{CD}^{+} \mathrm{T}$ cells upon DC differentiation. Even more important, presentation of circulating antigen by moDCs could trigger the expansion of autologous, HBV-specific T cells present in chronic HBV patients. MNs have been shown to capture systemic antigen in mice and activate $\mathrm{CD}^{+}$ $\mathrm{T}$ cells but (40), to our knowledge, this is the first demonstration that persistent antigen present in chronically infected patients can be utilized to stimulate their own virus-specific T cells. The caveat to exploiting this approach in chronic HBV patients is the level of exhaustion present in the virus-specific T cell compartment. After years of exposure to high levels of viral antigen, T cells either display an exhausted phenotype $(23,24,41,42)$ or are deleted $(22,43)$. However, recent data has shown that younger patients ( $<30$ years) still possess HBV-specific T cells (20) and long-term antiviral therapy can, at least partially, restore HBV-specific T cells in adults (21). Therefore, applying this approach in patients under successful antiviral therapy would likely be the best route to expanding endogenous T cells using circulating antigen captured by CD14 MNs.

The magnitude of HBV-specific T cell expansion in the autologous moDC experiments was variable among the different patients and lower relative to peptide-expanded cells. This suggests that the 

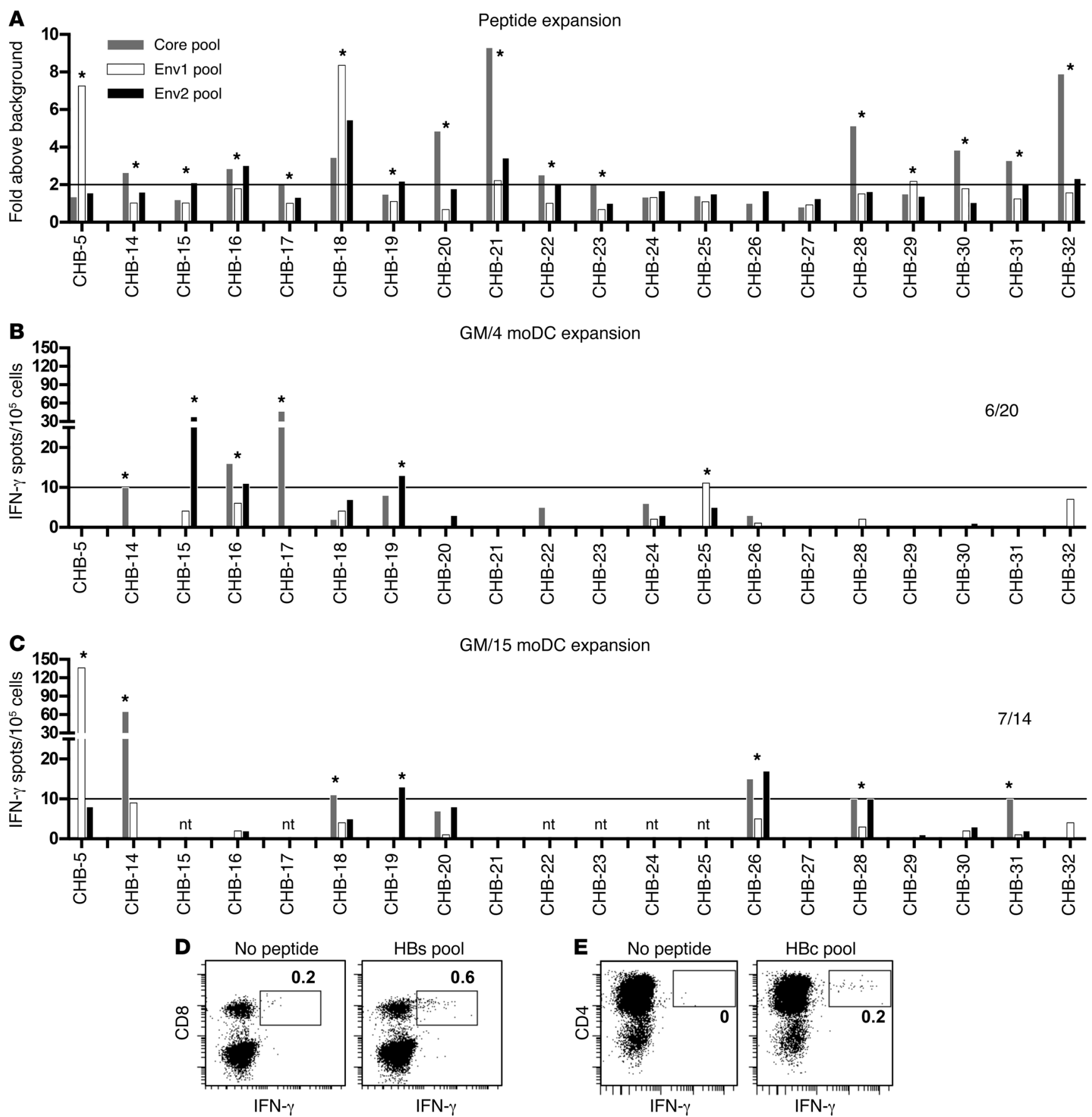

GM/15 moDC expansion

Figure 7

Expansion of autologous T cells by moDCs presenting in vivo-captured antigen. (A) IFN- $\gamma$ ELISPOT for chronic HBV patient virus-specific T cells expanded with pools of synthetic peptides covering HBcAg ( 1 pool $=$ core, 42 peptides) and HBsAg ( 2 pools = Env1 and Env2; 42 peptides each). Data displayed as fold above background to normalize variation among patients due to varying background for each assay. Positive cutoff was greater than 10 spots and 2 times the background. (B) IFN- $\gamma$ ELISPOT for chronic patient virus-specific T cells after expansion with moDCs made using GM-CSF + IL-4. (C) IFN- $\gamma$ ELISPOT for chronic patient virus-specific T cells after expansion with moDCs made using GM-CSF + IL-15. Positive responses for moDCs were defined as greater than 2 times the average of unstimulated wells and 10 or more spots. Background and responses for the moDC assays were lower than in peptide-expanded cultures and thus are presented as IFN- $\gamma$ spots/105 cells. Intracellular cytokine staining to confirm (D) CD8 ${ }^{+}$and (E) CD4+ HBV-specific T cell expansion with moDCs presenting in vivo captured antigen. Cytokine staining shows responses from 2 separate patients and is representative of 4 patients where responses could be detected by intracellular staining. *Positive response; nt, not tested. 
capacity of moDCs to stimulate autologous HBV-specific T cells can be further augmented. Our attempts to achieve this by blocking PD-L1 and CTLA-4 or using drugs inhibiting Bim-mediated T cell apoptosis failed to boost $\mathrm{T}$ cell expansion. In contrast, the differentiation programs used to make moDCs did appear to affect the expansion of HBV-specific T cells. GM/15-DCs have been shown to efficiently activate $\mathrm{CD}^{+} \mathrm{T}$ cells $(25)$ and induce responses in a higher frequency of patients than GM/4-DCs, which has also been observed in other studies (44). Thus, there may be a level of flexibility in how MNs can be targeted to efficiently harness their antigenic depot. We also have to consider that the ex vivo experiments remove CD14 MNs from their source of antigen, inherently limiting the number of peptide-MHC-I complexes that moDCs can present after differentiation. These experiments also do not account for the ability of DCs to prime new T cell responses, something that may be possible in vivo but will not be evident after 10 days of in vitro expansion. Therefore, our data demonstrate the potential of this strategy but could result in underestimation of the effect of successfully targeting CD14 MNs in vivo.

The mechanism by which MNs are mobilized to cross-present their antigenic depot is under investigation. We simply showed that CD14 MNs are positive for HBsAg ex vivo by fluorescent microscopy, but future studies will investigate where this antigen depot resides. The location of antigen within early or late endosomes can have a dramatic impact on the efficiency of cross-presentation (45), and this could be related to why alternate differentiation programs result in different levels of autologous $\mathrm{T}$ cell expansion. How the antigen traffics and is handled upon differentiation will be important to understanding the molecular mechanism (46) and could allow for further optimization of this approach.

Ultimately, we believe we have identified a previously unrecognized function of CD14 MNs during chronic HBV infection. This strategy may be extended to other persistent infections and potentially open new avenues for immunotherapy. Currently, in vitrocultured moDCs loaded with recombinant antigens have been used to vaccinate patients with chronic $\mathrm{HBV}(47,48), \mathrm{HCV}(49)$, and HIV (50-52) infection. These vaccines can enhance virus-specific T cell responses, but are hindered by the need to select appropriate antigens and a GMP cell production facility to produce the vaccine. The production costs associated with both of these aspects are often not affordable for patients living in regions where such diseases are common. Our data suggest that it could be possible to administer only adjuvants or cytokines for therapeutic vaccination, relying on the pathogen antigen present in chronically infected patients. If we can optimize this approach for in vivo application, it could eliminate the costly in vitro culture and selection of antigen for DC therapy and lead to a new, more accessible, form of immunotherapy.

\section{Methods}

Patient PBMCs. Blood was collected from 57 chronic HBV patients at the Barts and the London Hospital, Azienda Ospedaliero-Universitaria di Parma, and the National University Hospital in Singapore. PBMCs were isolated by Ficoll density gradient separation and cryopreserved in liquid nitrogen. PBMCs from healthy donors were obtained from the Blood Donation Center at the National University Hospital of Singapore. All patients used in antigen-specific $\mathrm{T}$ cell assays were confirmed to be HLAA0201 ${ }^{+}$and HLA-Cw0801 $1^{+}$by molecular-based HLA typing.

FACS sorting. PBMCs were stained with HLA-DR-Alexa Fluor 700, CD3-FITC, CD7-FITC, CD56-FITC (eBioscience); CD14-PeCy7, CD16APC-H7, CD20-Horizon V450, CD11c-APC (BD Biosciences); CD141-PE
(BDCA3; Miltenyi Bitotec); and CD123 PerCp-Cy5.5 (Biolegend) for 30 minutes at $4{ }^{\circ} \mathrm{C}$. Viability dyes, DAPI or Live/Dead Yellow Fixable Stain (Invitrogen), were used to gate on live cells followed by singlet gates. Cells were sorted on BD FACSAria III to greater than $98 \%$ purity. Data generated from the sorting files were used to calculate the frequency of APC populations in all subjects.

$M L R$. Sorted APC populations from healthy donors and chronic HBV patients were cocultured with cryopreserved total $\mathrm{T}$ cells isolated from a single healthy donor using RosetteSep Human T Cell Enrichment Cocktail (StemCell Technologies). T cells were labeled with CFSE (Invitrogen) and added at a 20:1 effector/target ratio (100,000 T cells:5,000 APCs) to sorted APCs and cultured for 7 days in AIM-V medium supplemented with $2 \%$ human $\mathrm{AB}$ serum (Invitrogen). T cells alone served as negative control, and $\mathrm{T}$ cells plus anti-CD3/anti-CD28 beads served as positive control. After 7 days, cells were stained with anti-CD3-Horizon V450 (BD Biosciences) and acquired on a BD LSR-II flow cytometer. Resulting data were then analyzed using the FlowJo Proliferation Platform to determine the division index and proliferation index of each APC population from healthy donors and chronic HBV patients. The division index is the average number of cell divisions that a cell in the original population has undergone. This is an average even for cells that never divided. The proliferation index was used to compare between patients and is defined as the average number of cell divisions that the responding cells underwent.

HBs Agstaining. APCs were sorted from chronic $\mathrm{HBV}$ patients as described above for fluorescent microscopy analysis. Sorted APCs were fixed with $1 \%$ paraformaldehyde for 15 minutes at room temperature. Fixed cells were then blocked with $0.25 \%$ saponin in PBS, $2 \%$ BSA, $5 \%$ goat serum (Serotec) for a minimum of 30 minutes and stained with polyclonal anti-HBsAgbiotin $(4.5 \mu \mathrm{g} / \mathrm{ml}$; Ad/Ay; Abcam) for 1 hour at room temperature. Cells were washed 2 times with $\mathrm{PBS} / 1 \% \mathrm{BSA} / 0.1 \%$ saponin and then stained with streptavidin-FITC or streptavidin-APC (BD Biosciences) for 30 minutes at room temperature. After 2 washes, cells were loaded onto Superfrost Plus Adhesion or Polysine slides (Thermo) and mounted with Prolong Gold Antifade + DAPI (Invitrogen), sealed, and acquired on a Tissuefax system (TissueGnostics). The Tissuefax system collects a digital image of the cytospin cells and calculates the intensity of FITC (HBsAg) fluorescence on DAPI-positive cells to give quantitative data on the frequency of $\mathrm{HBsAg}^{+}$cells in the APC population. FITC was chosen as the readout channel because this was used to gate out lineage CD3, CD7, and CD56 markers. Therefore, there were no FITC-positive markers on the APC populations. CD14 MNs were also sorted by single color staining using PeCy7 CD14 and isolated using CD14 microbeads to confirm that HBsAg staining was specific and not an artifact of the 9-color sorting panel. The relatively low quantity of HBsAg required a 2-step biotin-streptavidin staining and long exposure times (250-350 ms). As a result, autofluorescence and background staining were higher in CD14 MNs and reached up to $15 \%$ in some healthy donors. TissueQuest 3.0 was used to analyze fluorescent microscopy data, with a minimum of 25 fields of view analyzed for each cell population to obtain sufficient numbers for analysis.

Ex vivo antigen presentation assays. Sorted APC populations were as follows: CD11c DCs, CD141 DCs, CD123 pDCs, CD14 MNs, CD16 MNs, and CD20 $\mathrm{B}$ cells were cultured overnight in medium alone or under activating conditions $\pm 10 \mu \mathrm{g} / \mathrm{ml} \mathrm{rHBsAg}$ (provided by DynaVax). Cells were activated with $10 \mu \mathrm{g} / \mathrm{ml}$ poly(I:C) (TLR-3), $5 \mu \mathrm{M}$ CPG ODN2216 (TLR-9), $1 \mu \mathrm{g} / \mathrm{ml}$ LPS (TLR-4), $5 \mu \mathrm{g} / \mathrm{ml}$ Imiquimod (TLR-7), $1 \mu \mathrm{g} / \mathrm{ml}$ ssRNA40 (TLR-8) (InvivoGen), $1000 \mathrm{U} / \mathrm{ml}$ IFN- $\alpha$, or $1000 \mathrm{U} / \mathrm{ml}$ IFN- $\gamma$ (R\&D systems). Following overnight incubation, APC populations were thoroughly washed and transferred to anti-IFN- $\gamma$ coated ELISPOT plates and cocultured with $\mathrm{CD}^{+}$s183-TCR or s171-TCR redirected T cells at a 5:1 effector/target ratio (normally 5,000 APCs/well but as low as 1000 CD141 DCs/well) for 24 hours. APCs pulsed 
with $5 \mu \mathrm{g} / \mathrm{ml}$ HBs183-91(FLLTRILTI), HBs171-80 (FLGPLLVLQA), or HBc18-27 (FLPSDFFPSV) peptide served as positive controls for $\mathrm{T}$ cell activation. IFN- $\gamma$ ELISPOT was performed as described previously using $5 \mu \mathrm{g} / \mathrm{ml}$ of 1-D1K for capture and $0.5 \mu \mathrm{g} / \mathrm{ml}$ 7B6-1-Biotin plus streptavidin-ALP for detection (Mabtec) (19). ELISPOT plates were developed and analyzed using CTL Immunospot analyzer. Cut-off values for positive responses were set according to cumulative data from healthy donors and HLA-mismatched chronic HBV responses (data not shown). Wells were considered positive if responses were above 20 spot forming units $/ 50,000 \mathrm{~T}$ cells.

moDC generation and cross-presentation. $\mathrm{CD} 14^{+} \mathrm{MNs}$ were isolated from healthy donors and chronic HBV patients by FACS sorting or positive selection using CD14 microbeads (greater than 90\% purity; Miltenyi Biotec). Purified MNs were then cultured in RPMI 1640 supplemented with $10 \%$ heat-inactivated FBS, $20 \mathrm{mM}$ HEPES, $0.5 \mathrm{mM}$ sodium pyruvate, $100 \mathrm{U} / \mathrm{ml}$ penicillin, $100 \mu \mathrm{g} / \mathrm{ml}$ streptomycin, MeM amino acids, Glutamax, MeM nonessential amino acids, and $55 \mu \mathrm{M} 2$-mercaptoethanol (Invitrogen). GM-CSF + IL-4 moDCs were made by culturing CD14 MNs in $50 \mathrm{ng} / \mathrm{ml}(1500 \mathrm{U} / \mathrm{ml}) \mathrm{IL}-4$ and $50 \mathrm{ng} / \mathrm{ml}(750 \mathrm{U} / \mathrm{ml})$ GM-CSF (R\&D systems) for 6 days. GM-CSF + IL-15 (R\&D Systems) moDCs were made by culturing CD14 MNs in $100 \mathrm{ng} / \mathrm{ml}(1500 \mathrm{U} / \mathrm{ml}) \mathrm{GM}-\mathrm{CSF}+200 \mathrm{ng} / \mathrm{ml}$ IL-15. Half of the medium was removed after 3 days and replaced with complete RPMI containing cytokines. After 6 days of incubation, moDCs were stained with CD14-PerCp (Miltenyi Biotec), HLA-DR Alexa Fluor 700 (eBioscience), CD80-FITC (BD Bioscience), and CD86-APC (Biolegend) to confirm differentiation.

Six-day moDCs were cultured overnight in medium alone or activated with $10 \mu \mathrm{g} / \mathrm{ml}$ poly(I:C) or $0.1 \mu \mathrm{g} / \mathrm{ml} \mathrm{LPS} \mathrm{(Invivogen)}+50 \mathrm{ng} / \mathrm{ml}$ soluble HEK-derived CD40L (R\&D Systems). Following overnight incubation, moDCs were washed 3 times with HBSS and cocultured at a 2:1 effector/target ratio (10,000 T cells:5000 moDCs) with CD8 ${ }^{+} \mathrm{HBs} 183-91-$ or HBs171-80-specific TCR-redirected T cells for IFN- $\gamma$ ELISPOT. A cutoff for positive response, $25 \mathrm{IFN}-\gamma$ spots $/ 25,000 \mathrm{~T}$ cells for nonactivated moDCs and 35 IFN- $\gamma$ spots $/ 25,000 \mathrm{~T}$ cells for activated moDCs, was set based on the cumulative data of negative controls from healthy donors and HLA-mismatched chronic HBV patients (Figures 5 and 6).

To test cross-presentation from healthy donors, CD14 MNs were loaded with $\mathrm{HBV}$ antigen at day 0 (HBsAg 1-20 $\mu \mathrm{g} / \mathrm{ml})$ for 4 hours in complete RPMI and then differentiated to moDCs. Following the loading incubation at 0 days, 50,000 CD14 MNs were stained for HBsAg to confirm uptake.

Autologous T cell expansion with moDCs. Patients PBMCs were expanded with synthetic 15-mer overlapping peptides as previously described (19). Briefly, $20 \%$ of PBMCs were loaded with $10 \mu \mathrm{g} / \mathrm{ml}$ peptide pools covering the whole $\mathrm{HBcAg}$ and HBsAg and incubated for 1 hour at $37^{\circ} \mathrm{C}$. Peptide-loaded cells were washed and mixed back with remaining PBMCs and expanded in vitro for 10 days in Aim- $V+2 \%$ human AB serum + $20 \mathrm{U} / \mathrm{ml}$ IL-2 (R\&D Systems). After 10 days expansion, cells were stimulated with overlapping peptide pools and HBV-specific T cells were quantified using IFN- $\gamma$ ELISPOT. Positive responses were defined as 2 times the mean of unstimulated wells.

For autologous moDC expansion, CD14 MNs were isolated and differentiated for 6 days in the conditions described above. On day 6, moDCs were activated with LPS and CD40L for 24 hours and then mixed with autologous PBMCs at a 1:10 (moDC/PBMC) ratio. Cells were incubated for 10 days in Aim-V 2\% human AB serum + 20 U/ml IL-2. After 10 days, $T$ cell responses were tested using IFN- $\gamma$ ELISPOT with overlapping peptides. Positive cutoff for moDC-expanded T cells was 2 times the mean of unstimulated wells or greater than 10 spots. When cell numbers permitted, positive responses to moDC expansion were tested by intracellular cytokine staining for IFN- $\gamma$ to confirm elispot responses.

Statistics. Statistical analysis was performed on the APC population frequency in different patients categorized by viral load and liver inflammation and responses in the MLR assay using 1-way ANOVA and Tukey's post-test analysis.

Study approval. All patients gave informed consent.

Note added in proof. Recent data from a phase III therapeutic vaccine trial showed that administering adjuvant alone (alum) led to a clinically significant response, even better than that using alum plus HBsAg, suggesting that adjuvant alone is capable of inducing immunity using viral antigen present within the patient as a result of the chronic infection (53).

\section{Acknowledgments}

I would like to thank the flow cytometry core facilities at the Singapore Immunology Network and Singapore Institute for Clinical Sciences for all the help with sorting so many patients; Gijs Grotenbreg at the National University of Singapore for providing tetramers for the HLA-Cw0801-specific TCR redirected T cells; and DynaVax for providing the rHBsAg. This work was supported by funding from the Agency for Science, Technology, and Research ( $A^{*}$ Star).

Received for publication July 27, 2012, and accepted in revised form June 6, 2013.

Address correspondence to: Adam J. Gehring, Molecular Microbiology and Immunology Department, Saint Louis University Medical Center, Edward A. Doisy Research Center, Rm 713, 1100 South Grand, St. Louis, Missouri 63104, USA. Phone: 314.977.8711; Fax: 314.977.8717; E-mail: gehringa@slu.edu.
1. Seeger C, Mason WS. Hepatitis B virus biology. Microbiol Mol Biol Rev. 2000;64(1):51-68.

2. Wherry EJ. T cell exhaustion. Nat Immunol. 2011; 12(6):492-499.

3. Untergasser A, et al. Dendritic cells take up viral antigens but do not support the early steps of hepatitis B virus infection. Hepatology. 2006;43(3):539-547.

4. Bohm W, et al. Exogenous hepatitis B surface antigen particles processed by dendritic cells or macrophages prime murine MHC class I-restricted cytotoxic T lymphocytes in vivo. J Immunol. 1995; 155(7):3313-3321.

5. Stober D, Trobonjaca Z, Reimann J, Schirmbeck R. Dendritic cells pulsed with exogenous hepatitis $B$ surface antigen particles efficiently present epitopes to MHC class I-restricted cytotoxic T cells. Eur J Immunol. 2002;32(4):1099-1108.

6. Schirmbeck R, Bohm W, Melber K, Reimann J. Processing of exogenous heat-aggregated (denatured) and particulate (native) hepatitis B surface antigen for class I-restricted epitope presentation.JImmunol.
1995;155(10):4676-4684.

7. Schirmbeck R, Melber K, Reimann J. Hepatitis B virus small surface antigen particles are processed in a novel endosomal pathway for major histocompatibility complex class I-restricted epitope presentation. Eur J Immunol. 1995;25(4):1063-1070.

8. Barnaba V, Franco A, Alberti A, Benvenuto R, Balsano F. Selective killing of hepatitis B envelope antigen-specific B cells by class I-restricted, exogenous antigen-specific T lymphocytes. Nature. 1990; 345(6272):258-260.

9. Lazdina $U$, et al. Priming of cytotoxic T cell responses to exogenous hepatitis B virus core antigen is B cell dependent. J Gen Virol. 2003;84(pt 1):139-146.

10. Thimme R, et al. CD8(+) T cells mediate viral clearance and disease pathogenesis during acute hepatitis B virus infection. J Virol. 2003;77(1):68-76.

11. Tavakoli S, et al. Peripheral blood dendritic cells are phenotypically and functionally intact in chronic hepatitis B virus (HBV) infection. Clin Exp Immunol. 2008;151(1):61-70.
12. Gehring AJ, et al. Engineering virus-specific T cells that target HBV infected hepatocytes and hepatocellular carcinoma cell lines.J Hepatol. 2011;55(1):103-110.

13. Di Pucchio T, et al. Direct proteasome-independent cross-presentation of viral antigen by plasmacytoid dendritic cells on major histocompatibility complex class I. Nat Immunol. 2008;9(5):551-557.

14. Hoeffel G, et al. Antigen crosspresentation by human plasmacytoid dendritic cells. Immunity. 2007;27(3):481-492.

15. Bachem A, et al. Superior antigen cross-presentation and XCR1 expression define human CD11 + CD141+ cells as homologues of mouse CD8+ dendritic cells. JExp Med. 2010;207(6):1273-1281.

16. Jongbloed SL, et al. Human CD141+ (BDCA-3)+ dendritic cells (DCs) represent a unique myeloid DC subset that cross-presents necrotic cell antigens. J Exp Med. 2010;207(6):1247-1260.

17. Poulin LF, et al. Characterization of human DNGR-1+ BDCA3+ leukocytes as putative equivalents of mouse CD8alpha+ dendritic cells. J Exp 
Med. 2010;207(6):1261-1271.

18. Haniffa M, et al. Human tissues contain CD141(hi) cross-presenting dendritic cells with functional homology to mouse CD103(+) nonlymphoid dendritic cells. Immunity. 2012;37(1):60-73.

19. Tan AT, et al. Host ethnicity and virus genotype shape the hepatitis B virus-specific T-cell repertoire. J Virol. 2008;82(22):10986-10997.

20. Kennedy P, et al. Preserved T-cell function in children and young adults with immune-tolerant chronic hepatitis B. Gastroenterology. 2012; 143(3):637-645.

21. Boni C, et al. Restored function of HBV-specific $\mathrm{T}$ cells after long-term effective therapy with nucleos(t)ide analogues. Gastroenterology. 2012; 143(4):e963-e969.

22. Maini MK, et al. The role of virus-specific CD8(+) cells in liver damage and viral control during persistent hepatitis B virus infection. J Exp Med. 2000 191(8):1269-1280.

23. Lopes AR, et al. Bim-mediated deletion of antigenspecific CD8 T cells in patients unable to control HBV infection. J Clin Invest. 2008;118(5):1835-1845.

24 . Schurich A, et al. Role of the coinhibitory receptor cytotoxic T lymphocyte antigen-4 on apoptosisProne CD8 T cells in persistent hepatitis B virus infection. Hepatology. 2011;53(5):1494-1503.

25. Mohamadzadeh $\mathrm{M}$, et al. Interleukin 15 skews monocyte differentiation into dendritic cells with features of Langerhans cells. J Exp Med. 2001; 194(7):1013-1020.

26. Beckebaum S, et al. Reduction in the circulating $\mathrm{pDC} 1 / \mathrm{pDC} 2$ ratio and impaired function of ex vivogenerated DC1 in chronic hepatitis B infection. Clin Immunol. 2002;104(2):138-150

27. Beckebaum S, et al. Hepatitis B virus-induced defect of monocyte-derived dendritic cells leads to impaired T helper type 1 response in vitro: mechanisms for viral immune escape. Immunology. 2003; 109(4):487-495.

28. Op den Brouw ML, et al. Hepatitis B virus surface antigen impairs myeloid dendritic cell function: a possible immune escape mechanism of hepatitis B virus. Immunology. 2009;126(2):280-289.

29. Shimizu Y, Guidotti LG, Fowler P, Chisari FV. Dendritic cell immunization breaks cytotoxic T lymphocyte tolerance in hepatitis B virus transgenic mice. J Immunol. 1998;161(9):4520-4529.

30. Tavakoli S, et al. Phenotype and function of mono- cyte derived dendritic cells in chronic hepatitis B virus infection. J Gen Virol. 2004;85(pt 10):2829-2836.

31. van der Molen RG, Sprengers D, Biesta PJ, Kusters JG, Janssen HL. Favorable effect of adefovir on the number and functionality of myeloid dendritic cells of patients with chronic HBV. Hepatology. 2006; 44(4):907-914

32. van der Molen RG, et al. Functional impairment of myeloid and plasmacytoid dendritic cells of patients with chronic hepatitis B. Hepatology. 2004; 40(3):738-746

33. Woltman AM, Op den Brouw ML, Biesta PJ, Shi CC, Janssen HL. Hepatitis B virus lacks immune activating capacity, but actively inhibits plasmacytoid dendritic cell function. PLoS One. 2011;6(1):e15324.

34. Xie Q, et al. Patients with chronic hepatitis B infection display deficiency of plasmacytoid dendritic cells with reduced expression of TLR9. Microbes Infect. 2009; 11(4):515-523.

35. Wu J, et al. Hepatitis B virus suppresses toll-like receptor-mediated innate immune responses in murine parenchymal and nonparenchymal liver cells. Hepatology. 2009;49(4):1132-1140.

36. Bowen DG, Zen M, Holz L, Davis T, McCaughan GW, Bertolino P. The site of primary T cell activation is a determinant of the balance between intrahepatic tolerance and immunity. J Clin Invest. 2004; 114(5):701-712.

37. Ebrahimkhani MR, Mohar I, Crispe IN. Cross-presentation of antigen by diverse subsets of murine liver cells. Hepatology. 2011;54(4):1379-1387.

38. Limmer A, et al. Efficient presentation of exogenous antigen by liver endothelial cells to CD8+ T cells results in antigen-specific T-cell tolerance. Nat Med. 2000;6(12):1348-1354

39. Hou W, et al. Viral infection triggers rapid differentiation of human blood monocytes into dendritic cells. Blood. 2012;119(13):3128-3131.

40. Tacke F, Ginhoux F, Jakubzick C, van Rooijen N, Merad M, Randolph GJ. Immature monocytes acquire antigens from other cells in the bone marrow and present them to $\mathrm{T}$ cells after maturing in the periphery. J Exp Med. 2006;203(3):583-597.

41. Boni C, et al. Characterization of hepatitis B virus (HBV)-specific T-cell dysfunction in chronic HBV infection. J Virol. 2007;81(8):4215-4225.

42. Das A, et al. Functional skewing of the global CD8 $\mathrm{T}$ cell population in chronic hepatitis B virus infection. J Exp Med. 2008;205(9):2111-2124.
43. Webster GJ, et al. Longitudinal analysis of CD8+ $T$ cells specific for structural and nonstructural hepatitis B virus proteins in patients with chronic hepatitis B: implications for immunotherapy. J Virol. 2004;78(11):5707-5719.

44. Dubsky P, et al. IL-15-induced human DC efficiently prime melanoma-specific naive CD8+ T cells to differentiate into CTL. Eur J Immunol. 2007; 37(6):1678-1690.

45. Chatterjee B, et al. Internalization and endosomal degradation of receptor-bound antigens regulate the efficiency of cross presentation by human dendritic cells. Blood. 2012;120(10):2011-2020.

46. Delamarre L, Pack M, Chang H, Mellman I, Trombetta ES. Differential lysosomal proteolysis in antigen-presenting cells determines antigen fate. Science. 2005;307(5715):1630-1634.

47. Carotenuto P, Artsen A, Niesters HG, Osterhaus $\mathrm{AD}$, Pontesilli $\mathrm{O}$. In vitro use of autologous dendritic cells improves detection of $\mathrm{T}$ cell responses to hepatitis B virus (HBV) antigens. J Med Virol. 2009; 81(2):332-339.

48. Shi M, et al. Hepatitis B virus (HBV) antigen-pulsed monocyte-derived dendritic cells from HBV-associated hepatocellular carcinoma patients significantly enhance specific $\mathrm{T}$ cell responses in vitro. Clin Exp Immunol. 2007;147(2):277-286.

49. Gowans EJ, et al. A phase I clinical trial of dendritic cell immunotherapy in HCV-infected individuals. J Hepatol. 2010;53(4):599-607.

50. Fan Z, Huang XL, Borowski L, Mellors JW, Rinaldo CR. Restoration of anti-human immunodeficiency virus type 1 (HIV-1) responses in CD8+ T cells from late-stage patients on prolonged antiretroviral therapy by stimulation in vitro with HIV-1 protein-loaded dendritic cells. JVirol. 2001;75(9):4413-4419.

51. Lu W, Andrieu JM. In vitro human immunodeficiency virus eradication by autologous CD8(+) T cells expanded with inactivated-virus-pulsed dendritic cells. J Virol. 2001;75(19):8949-8956.

52. Van Gulck ER, et al. Efficient in vitro expansion of human immunodeficiency virus (HIV)-specific T-cell responses by gag mRNA-electroporated dendritic cells from treated and untreated HIV type 1-infected individuals. JVirol. 2008;82(7):3561-3573.

53. Xu D-Z, et al. Results of a phase III clinical trial with an HbsAg-HBIG Immunogenic complex therapeutic vaccine for chronic hepatitis B patients: experiences and findings. J Hepatol. In press. 